\title{
GAMBARAN PENGETAHUAN CARA MENYIKAT GIGI SISWA-SISWI KELAS V SD NEGERI 050633 MOJOSARI KECAMATAN KUALA KABUPATEN LANGKAT SEBELUM DANSESUDAH DIBERIKAN PENYULUHAN METODE DEMONSTRASI
}

\author{
Kirana Patrolina Sihombing \\ Jurusan Keperawatan Gigi Poltekkes Kemenkes Medan
}

\begin{abstract}
Abstrak
Usia sekolah dasar merupakan usia yang ideal untuk melatih kemampuan motorik seorang anak, termasuk di antaranya menyikat gigi. Metode demonstrasi pada penyuluhan kesehatan gigi dan mulut efektif dalam mendukung meningkatnya pemahaman anak, dengan mempraktekkan secara langsung cara menyikat gigi yang benar. Penelitian ini adalah penelitian deskriptif yang bertujuan untuk mengetahui gambaran pengetahuan cara menyikat gigi siswa-siswi kelas V SD Negeri 050633 Mojosari Kecamatan Kuala Kabupaten Langkat sebelum dan sesudah diberikan penyuluhan metode demonstrasi. Jenis penelitian ini adalah deskriptif dengan pendekatan cross sectional untuk mengukur pengetahuan cara menyikat gigi sebelum dan sesudah diberikan penyuluhan metode demonstrasi pada responden sejumlah 30 orang berusia antara usia 10-11 tahun. Hasil penelitian menunjukkan Tingkat pengetahuan siswa Kelas V SD usia 10-11 tahun di SD Negeri 050633 Mojosari Kecamatan Kuala Kabupaten Langkat sebelum diberi penyuluhan metode demonstrasi masih termasuk kriteria kurang (70\%), dan kriteria cukup (30\%), dan sesudah diberi penyuluhan metode demonstrasi meningkat menjadi kriteria baik sebesar $83,3 \%$ dan hanya $16,7 \%$ yang termasuk kriteria cukup. Kesimpulan penelitian ini adalah terdapatnya perubahan pengetahuan siswa-siswi kelas V SD Negeri 050633 Mojosari Kecamatan Kuala Kabupaten Langkat sebelum dan sesudah diberikan penyuluhan metode demonstrasi.
\end{abstract}

Kata Kunci: Pengetahuan, Demonstrasi, Menyikat gigi

\section{PENDAHULUAN}

Gigi dan mulut anak yang kurang terpelihara kebersihannya, akan rentan terhadap penyakit karies yang menyebabkan keluhan sakit dan berisiko kehilangan gigi lebih cepat (Budiharto, 2008). Kerusakan pada gigi dapat mempengaruhi kesehatan anggota tubuh yang lain, sehingga mengganggu aktivitas sehari - hari. Berdasarkan hasil Riset Kesehatan Dasar (Riskesdas) Tahun 2013, prevalensi penduduk Indonesia yang mempunyai masalah pada kesehatan gigi dan mulutnya termasuk karies gigi dan penyakit periodontal meningkat sebesar $25,9 \%$ dimana kelompok anak usia 10-14 tahun lebih sering bermasalah pada kesehatan gigi dan mulutnya dengan persentase sebesar $25,2 \%$.

Timbulnya masalah kesehatan gigi dan mulut pada masyarakat salah satunya disebabkan oleh faktor perilaku atau sikap mengabaikan kebersihan gigi dan mulut. Hal ini dilandasi oleh karena kurangnya pengetahuan akan pentingnya pemeliharaan kesehatan gigi dan mulut. Masalah gigi terbesar terjadi pada anakanak karena anak-anak kurang mengetahui cara menjaga kesehatan gigi dan mulutnya. Sebanyak 15 propinsi di Indonesia memiliki data menyikat gigi setiap hari adalah 94,2 persen masih berada dibawah prevalensi nasional (Riskesdas, 2013). Menyikat gigi dengan benar adalah setelah makan pagi dan sebelum tidur malam. Namun sebagian besar penduduk Indonesia menyikat gigi pada saat mandi pagi maupun mandi sore $(76,6 \%)$ dan hanya 2,3 persen untuk menyikat gigi dengan benar (Riskesdas, 2013). Propinsi Sumatera Utara meduduki posisi ke 28 dengan angka 19,4\% yang menyikat gigi dengan benar.

Tindakan menyikat gigi merupakan salah satu upaya pencegahan dari karies gigi. Salah satu program Usaha Kesehatan Gigi Sekolah (UKGS) adalah melaksanakan penyuluhan kesehatan gigi dan mulut agar siswa memiliki pengetahuan serta dapat memelihara diri dengan baik khususnya dalam memelihara kesehatan gigi dan mulut (Herijulianti, 2002). Penyuluhan kesehatan gigi dan mulut pada murid sekolah dasar merupakan salah satu upaya untuk meningkatkan pengetahuan dalam menjaga kebersihan gigi dan mulut sehingga derajat kesehatan gigi pada anak dalam aspek promotif dan preventif meningkat. Penyuluhan kesehatan gigi ini tidak semata-mata menjadi tanggung jawab pemerintah, akan tetapi merupakan tanggung jawab semua pihak. Penekanan konsep penyuluhan kesehatan lebih kepada upaya memperbaiki perilaku sasaran agar berperilaku sehat, terutama aspek kognitif, sehingga pengetahuan sasaran penyuluhan sesuai dengan yang diharapkan oleh penyuluh kesehatan maka penyuluhan berikutnya akan dijalankan sesuai dengan program yang telah direncanakan (Simon dkk, 2010).

Pemilihan metode demonstrasi pada penyuluhan kesehatan gigi dan mulut dapat mendukung meningkatnya 
pemahaman anak, dengan mempraktekkan secara langsung cara menyikat gigi yang benar. Penggunaan alat bantu dalam metode demonstrasi menyikat gigi akan memudahkan penyerapan pengetahuan. Penyuluhan dengan metode demonstrasi' tergolong alat bantu atau alat peraga yang memiliki intensitas tinggi (menduduki tingkatan ke-8) dalam mempersepsikan bahan pendidikan atau pengajaran, sedangkan pendidikan kesehatan gigi dan mulut yang dilakukan hanya dengan kata-kata memiliki intensitas paling rendah untuk mempersepsikan pendidikan yang diberikan. Seseorang mampu mengingat informasi sebanyak $50 \%$ dari apa yang mereka lihat dan dengar, dan sebanyak $80 \%$ informasi yang mereka peroleh jika mereka melihat, mendengar, dan melakukan informasi tersebut secara bersama-sama (Kumboyono, 2011)

Usia sekolah dasar merupakan saat yang ideal untuk melatih kemampuan motorik seorang anak, termasuk di antaranya menyikat gigi. Bagi anak, cara menyikat gigi perlu diberikan contoh suatu model yang baik serta dengan teknik yang sederhana mungkin. Penyampaian pendidikan kesehatan gigi dan mulut pada anak-anak harus dibuat semenarik mungkin, antara lain melalui penyuluhan yang atraktif tanpa mengurangi isi pendidikan, demonstrasi secara langsung, program audiovisual, atau melalui sikat gigi massal yang terkontrol. Pemilihan metode demonstrasi pada penyuluhan kesehatan gigi dan mulut mendukung meningkatnya pemahaman anak, dengan mempraktekkan secara langsung cara menyikat gigi yang benar (Hariyanti, 2008).

Berhasilnya pemeliharaan kesehatan gigi dan mulut juga dipengaruhi oleh faktor penggunaan alat, metode penyikatan gigi, serta frekuensi dan waktu penyikatan yang tepat (Situmorang, 2008). Kelompok anak usia sekolah dasar termasuk kelompok rentan untuk terjadinya kasus kesehatan gigi dan mulut, sehingga perlu diwaspadai atau dikelola secara baik dan benar (Darwita, 2011). Berdasarkan hasil survey di SD Negeri 050633 Mojosari Kecamatan Kuala Kabupaten Langkat kebanyakan siswa-siswi menyikat gigi masih dengan cara yang salah, dan waktu menyikat gigi hanya saat mandi. Kepedulian dan pengetahuan siswa-siswi maupun guru terhadap kesehatan gigi dan mulut masih rendah terbukti dari hasil wawancara dengan para guru diperoleh informasi bahwa kesehatan gigi belum dianggap penting karena penyuluhan ke sekolah jarang dilaksanakan. Oleh karena latar belakang di atas maka peneliti tertarik utuk meneliti bagaimana bagaimana gambaran pengetahuan cara menyikat gigi siswa-siswi kelas V SD Negeri 050633 Mojosari Kecamatan Kuala Kabupaten Langkat sebelum dan sesudah diberikan penyuluhan metode demonstrasi.

\section{METODE}

\section{Jenis dan Desain Penelitian}

Jenis penelitian yang akan dilakukan adalah penelitian deskriptif dengan rancangan cross sectional. Penelitian ini akan mengamati gambaran pengetahuan cara menyikat gigi siswa-siswi kelas V SD Negeri 050633
Mojosari Kecamatan Kuala Kabupaten Langkat sebelum dan sesudah diberikan penyuluhan metode demonstrasi.

\section{Populasi dan Sampel Penelitian}

Populasi penelitian ini adalah seluruh siswasiswi SD Negeri 050633 Mojosari Kecamatan Kuala Kabupaten Langkat berjumlah 156 orang. Sampel dipilih kelas IV dan V sebanyak 30 orang dengan kriteria usia 10-12 tahun, dan bersedia ikut berpartisipasi dalam penelitian.

\section{Jenis dan Cara Pengumpulan Data}

Dalam penelitian ini data primer adalah tingkat pengetahuan cara menyikat gigi yang diperoleh dari jawaban kuesioner yang diberikan sebelum dan sesudah diberikan penyuluhan metode demonstrasi cara menyikat gigi, sedangkan data sekunder meliputi data identitas sampel yang diperoleh dari pihak sekolah.

Tahap pelaksanaan meliputi membagikan kuesioner pre-test sebelum dilakukan penyuluhan , menyiapkan materi penyuluhan tentang menyikat gigi, mengumpulkan responden pada ruang yang telah dipersiapkan, melakukan penyuluhan metode demonstrasi cara menyikat gigi, dan membagikan kuesioner post-test setelah dilakukan penyuluhan.

Pengukuran pengetahuan responden didapat dari pertanyaan kuesioner. Kuesioner terdiri dari 15 pertanyaan dimana untuk setiap pertanyaan yang dijawab benar diberi nilai 1 dan jika salah diberi nilai 0 . Nilai tertinggi yang diperoleh adalah 15 dan terendah adalah 0 . Pengelompokan kategori pengetahuan terdiri dari 3 (tiga) kelompok yaitu baik, cukup, kurang. Maka

$\frac{\text { skor maksimum-skor minimum }}{\text { Jumlah kategori }}=15-0=5$

Maka :

0-5 : Pengetahuan kurang

6-10 : Pengetahuan cukup

11-15 : Pengetahuan baik

\section{Analisa Data}

Pada penelitian ini data yang diperoleh dari hasil sebelum dan sesudah pelaksanaan penyuluhan akan disajikan dalam distribusi frekuensi. Proses pengolahan data harus melalui Editing, Coding, Data Entry, dan Cleaning.

\section{HASIL}

Penelitian ini telah dilakukan pada 30 orang anak usia usia 10-11 tahun di Kelas V SD Negeri 050633 Mojosari Kecamatan Kuala Kabupaten Langkat. Pengambilan data sampel dilakukan selama 1 minggu dimana pengumpulan data diperoleh dari kuesioner yang disebar sebelum dan sesudah diberikan penyuluhan metode demonstrasi.

Data Pengetahuan subjek sebelum dan sesudah diberikan penyuluhan cara menyikat gigi dengan metode demonstrasi dapat dilihat pada tabel berikut :

\section{Tabel 1.}




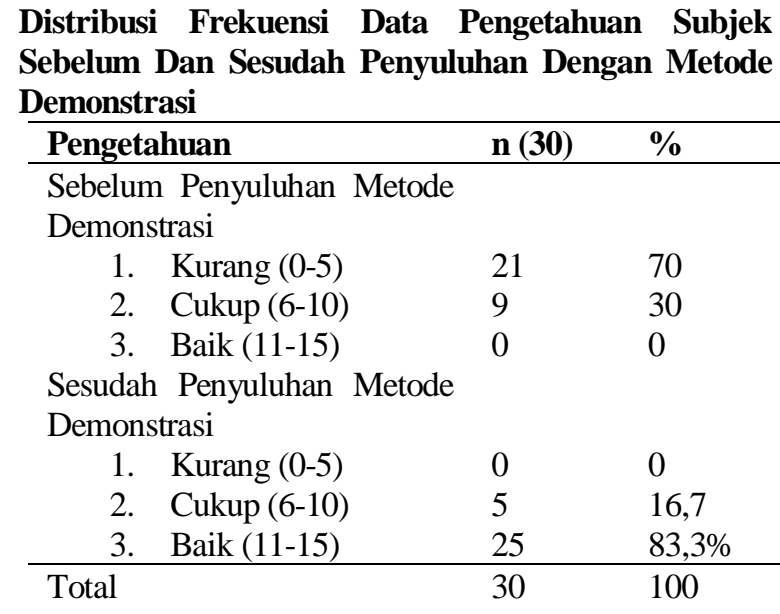

Berdasarkan data tabel 1 diatas, persentase pengetahuan subjek sebelum penyuluhan metode demonstrasi terbanyak memiliki kriteria kurang yaitu $70 \%$, namun persentase pengetahuan subjek sesudah penyuluhan metode demonstrasi berubah menjadi kriteria baik sebanyak $83,3 \%$ dan hanya $16,7 \%$ yang kategori cukup. Hasil penghitungan kuesioner pengetahuan subjek diakumulasi dalam tabel berikut.

Tabel 2.

Distribusi

Frekuensi

Jawaban

KuesionerPengetahuan Subjek Sebelum Dan Sesudah Penyuluhan Metode Demonstrasi

\begin{tabular}{|c|c|c|c|c|c|c|c|c|c|}
\hline \multirow[t]{3}{*}{ No } & \multirow[t]{3}{*}{ Pernyataan } & \multicolumn{4}{|c|}{ Sebelum } & \multicolumn{4}{|c|}{ Sesudah } \\
\hline & & \multicolumn{2}{|c|}{ Benar } & \multicolumn{2}{|c|}{ Salah } & \multicolumn{2}{|c|}{ Benar } & \multicolumn{2}{|c|}{ Salah } \\
\hline & & $\mathbf{n}$ & $\%$ & $\mathbf{n}$ & $\%$ & $\mathbf{n}$ & $\%$ & $\mathbf{n}$ & $\%$ \\
\hline 1 & $\begin{array}{l}\text { Penyebab gigi } \\
\text { berlubang }\end{array}$ & $\begin{array}{l}1 \\
0\end{array}$ & $\begin{array}{l}33, \\
3\end{array}$ & $\begin{array}{l}2 \\
0\end{array}$ & $\begin{array}{l}66, \\
7\end{array}$ & $\begin{array}{l}2 \\
2\end{array}$ & $\begin{array}{l}73, \\
3\end{array}$ & 8 & $\begin{array}{l}26, \\
7\end{array}$ \\
\hline 2 & $\begin{array}{l}\text { Cara } \\
\text { mencegah gigi } \\
\text { berlubang }\end{array}$ & $\begin{array}{l}1 \\
2\end{array}$ & 40 & $\begin{array}{l}1 \\
8\end{array}$ & 60 & $\begin{array}{l}2 \\
6\end{array}$ & $\begin{array}{l}86, \\
6\end{array}$ & 4 & $\begin{array}{l}13, \\
4\end{array}$ \\
\hline 3 & $\begin{array}{l}\text { Cara } \\
\text { membersihka } \\
\text { n Sisa } \\
\text { makanan di } \\
\text { dalam mulut }\end{array}$ & $\begin{array}{l}1 \\
9\end{array}$ & $\begin{array}{l}63, \\
3\end{array}$ & $\begin{array}{l}1 \\
1\end{array}$ & $\begin{array}{l}36, \\
6\end{array}$ & $\begin{array}{l}2 \\
7\end{array}$ & 90 & 3 & 10 \\
\hline 4 & $\begin{array}{l}\text { Bulu sikat gigi } \\
\text { yang } \\
\text { dianjurkan } \\
\text { untuk } \\
\text { menyikat gigi }\end{array}$ & $\begin{array}{l}1 \\
8\end{array}$ & 60 & $\begin{array}{l}1 \\
2\end{array}$ & 40 & $\begin{array}{l}2 \\
6\end{array}$ & $\begin{array}{l}86, \\
6\end{array}$ & 4 & $\begin{array}{l}13, \\
4\end{array}$ \\
\hline 5 & $\begin{array}{l}\text { Menyikat gigi } \\
\text { harus } \\
\text { menggunakan } \\
\text { apa }\end{array}$ & $\begin{array}{l}1 \\
4\end{array}$ & $\begin{array}{l}46, \\
6\end{array}$ & $\begin{array}{l}1 \\
6\end{array}$ & $\begin{array}{l}53 \\
4\end{array}$ & $\begin{array}{l}2 \\
5\end{array}$ & $\begin{array}{l}83, \\
3\end{array}$ & 5 & $\begin{array}{l}16, \\
7\end{array}$ \\
\hline 6 & $\begin{array}{lr}\text { Cara } & \text { memilih } \\
\text { pasta } & \text { gigi } \\
\text { yang benar } \\
\text { untuk } \\
\text { menyikat gigi }\end{array}$ & $\begin{array}{l}2 \\
3\end{array}$ & $\begin{array}{l}76, \\
6\end{array}$ & 7 & $\begin{array}{l}23 \\
4\end{array}$ & $\begin{array}{l}2 \\
5\end{array}$ & $\begin{array}{l}83, \\
3\end{array}$ & 5 & $\begin{array}{l}16, \\
7\end{array}$ \\
\hline 7 & $\begin{array}{l}\text { Waktu } \\
\text { menyikat gigi } \\
\text { yang benar }\end{array}$ & $\begin{array}{l}1 \\
8\end{array}$ & 60 & $\begin{array}{l}1 \\
2\end{array}$ & 40 & $\begin{array}{l}2 \\
9\end{array}$ & $\begin{array}{l}96, \\
6\end{array}$ & 1 & 3,4 \\
\hline 8 & $\begin{array}{l}\text { Hal yang } \\
\text { harus } \\
\text { dilakukan } \\
\text { sebelum } \\
\text { menggosok } \\
\text { gigi }\end{array}$ & $\begin{array}{l}2 \\
0\end{array}$ & $\begin{array}{l}66, \\
6\end{array}$ & $\begin{array}{l}1 \\
0\end{array}$ & $\begin{array}{l}33 \\
4\end{array}$ & $\begin{array}{l}2 \\
6\end{array}$ & $\begin{array}{l}86, \\
6\end{array}$ & 4 & $\begin{array}{l}13, \\
4\end{array}$ \\
\hline 9 & $\begin{array}{l}\text { Cara menyikal } \\
\text { gigi yang }\end{array}$ & $\begin{array}{l}1 \\
6 \\
\end{array}$ & $\begin{array}{l}53, \\
3\end{array}$ & $\begin{array}{l}1 \\
4 \\
\end{array}$ & $\begin{array}{l}46, \\
7\end{array}$ & $\begin{array}{l}2 \\
0 \\
\end{array}$ & $\begin{array}{l}66, \\
6\end{array}$ & $\begin{array}{l}1 \\
0\end{array}$ & $\begin{array}{l}33, \\
4\end{array}$ \\
\hline
\end{tabular}

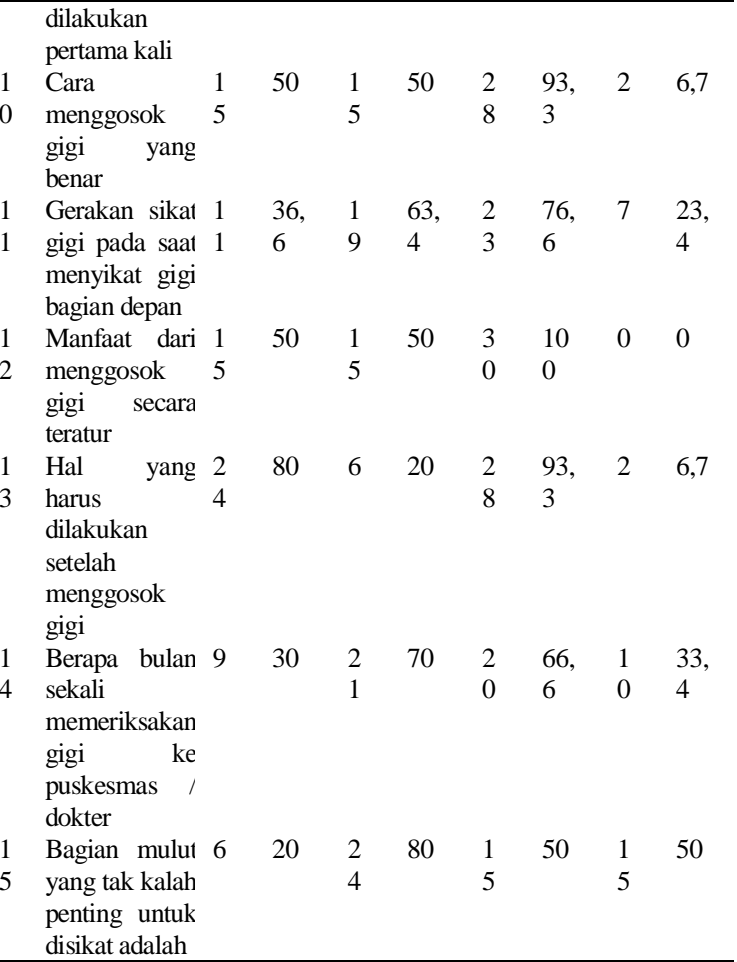

Berdasarkan tabel 2 diatas menunjukkan persentase jawaban benar terbanyak ada pada pertanyaan 8 dan 13 mencapai 66,6\% dan 80\%, sedangkan jawaban salah terbanyak ada pada pertanyaan 14 dan 15 masingmasing $70 \%$ dan $80 \%$. Setelah diberi penyuluhan metode demonstrasi, persentase jawaban benar terbanyak ada pada pertanyaan $7,10,12$, dan 13 masing masing $96,6 \%$, $93,3 \%, 100 \%$, dan $93,3 \%$, sedangkan jawaban pertanyaan yang salah paling banyak ada pada pertanyaan 9,14 , dan 15 masing-masing dan 33,4, 33\%, dan $50 \%$.

\section{PEMBAHASAN}

Berdasarkan hasil penelitian ini diketahui bahwa sebelum dilakukan penyuluhan cara menyikat gigi dengan metode demonstrasi, sebanyak $70 \%$ responden memiliki pengetahuan yang kurang tentang cara menyikat. Namun sesudah diberikan penyuluhan cara menyikat gigi dengan metode demonstrasi terjadi peningkatan menjadi $83,3 \%$ atau naik sebesar $13,3 \%$. Kemampuan menyikat gigi secara baik dan benar merupakan faktor yang cukup penting dalam pemeliharaan kesehatan gigi dan mulut. Keberhasilan kesehatan gigi dan mulut seseorang dipengaruhi oleh pengetahuan tentang penggunaan alat dan metode penyikatan gigi, frekuensi serta waktu penyikatan gigi yang tepat (Wendari, 2001). Menurut Sariningrum dkk., (2009) tingkat pengetahuan tentang kesehatan gigi dan mulut sangat berpengaruh terhadap perilaku subyek dalam memelihara kesehatan gigi dan mulut.

Berdasarkan 15 pertanyaan kuesioner yang diberikan, hanya 53,3\% subjek yang menjawab benar pertanyaan 9 tentang langkah pertama kali cara menyikat gigi, sebanyak $50 \%$ menjawab benar untuk pertanyaan nomor 10 tentang cara menggosok gigi yang benar, sebanyak 36,6\% yang menjawab benar tentang gerakan 
menyikat gigi yang benar pada pertanyaan nomor 11, dan hanya $50 \%$ responden yang benar menjawab pertanyaan nomor 12 tentang manfaat dari menggosok gigi secara teratur.

Setelah dilakukan penyuluhan metode demonstrasi terjadi peningkatan jawaban yang benar dari kuesioner penelitian dimana jawaban pertanyaan nomor 9 tentang langkah pertama kali cara menyikat gigi meningkat menjadi 93,3\%, jawaban pertanyaan nomor 10 tentang Cara menggosok gigi yang benar meningkat menjadi 93,3\%, jawaban pertanyaan nomor 11 tentang Gerakan sikat gigi pada saat menyikat gigi bagian depan meningkat menjadi $76,6 \%$, dan paling baik adalah jawaban pertanyaan nomor 12 tentang tentang manfaat dari menggosok gigi secara teratur meningkat seluruhnya menjadi $100 \%$.

Usia sekolah dasar merupakan saat yang ideal untuk melatih kemampuan motorik seorang anak, termasuk di antaranya menyikat gigi. Bagi anak, cara menyikat gigi perlu diberikan contoh suatu model yang baik serta dengan teknik yang sederhana mungkin. Penyampaian pendidikan kesehatan gigi dan mulut pada anak-anak harus dibuat semenarik mungkin, antara lain melalui penyuluhan yang atraktif tanpa mengurangi isi pendidikan, demonstrasi secara langsung, program audiovisual, atau melalui sikat gigi massal yang terkontrol. Menurut Hariyanti (2008) pemilihan metode demonstrasi pada penyuluhan kesehatan gigi dan mulut efektif dalam mendukung meningkatnya pemahaman anak, dengan mempraktekkan secara langsung cara menyikat gigi yang benar.

Dalam metode demonstrasi perhatian siswa dapat dipusatkan kepada hal-hal yang dianggap penting oleh pendidik. Disamping itu siswa pun lebih mudah memahami dan menghafalkan proses belajar mengajar. Penyuluhan peragaan ini dapat mengurangi kesalahankesalahan bila dibandingakan dengan hanya membaca atau mendengarkan, karena siswa mendapatkan gambaran yang jelas dari hasil pengamatan. Peragaan membantu anak mengingat bagian-bagian gigi yang biasa disikat sewaktu dirumah sehingga anak lebih mengerti ketika ditunjukkan bagian-bagian gigi yang harus disikat di alat peraga (Oki dkk, 2012).

\section{SIMPULAN}

Tingkat pengetahuan siswa Kelas V SD usia 10-11 tahun di SD Negeri 050633 Mojosari Kecamatan Kuala Kabupaten Langkat sebelum diberi penyuluhan metode demonstrasi masih termasuk kriteria kurang (70\%), dan kriteria cukup (30\%).

Tingkat pengetahuan siswa Kelas V SD usia 10-11 tahun di SD Negeri 050633 Mojosari Kecamatan Kuala Kabupaten Langkat sesudah diberi penyuluhan metode demonstrasi meningkat menjadi kriteria baik sebesar $83,3 \%$ dan hanya $16,7 \%$ yang termasuk kriteria cukup.

\section{SARAN}

Perlunya pihak sekolah mempromosikan program menyikat gigi secara berkelanjutan kepada siswa-siswi yang didemonstrasikan oleh guru maupun bekerjasama dengan puskesmas.

\section{DAFTAR PUSTAKA}

Damanik S, Sinaga ED. Efek penyuluhan dan pelatihan dalam penurunan indek plak pada murid-murid kelas IV dan V di dua SD negeri Medan. Dentika Dent J 2002; 7(1): 1-5.

Darwita, RR, dkk. (2011). Efektifitas Program Sikat Gigi Bersama Terhadap Risiko Karies Gigi pada Murid Sekolah Dasar. Journal Indonesia Mededical Association. Vol 61. No 5

Hariyanti, N, dkk. 2008. Mengatasi Kegagalan Penyuluhan Kesehatan Gigi pada Anak dengan Pendekatan Psikologi. Dentika Dental Journal. Vol 13. No 1.

Haryoko S. Efektivitas pemanfaatan media audio visual sebagai alternatif optimalkan model pembelajaran. Jurnal Edukasi Elektro 2009; 5:1-10

Herijulianti E, Indriani TS, Artini S. Pendidikan kesehatan gigi. Jakarta: EGC, 2001: 51-3, 66-76

Hurairah IA. Penyuluhan kesehatan gigi. 1 April $2011 . \quad<\mathrm{http}: / /$ ibnuabihurairai r.blogspot.com/2011/04/penyuluhan-

kesehatan-gigi-skripsi.html> . (10 April 2011)

Kumboyono. Perbedaan Efek Penyuluhan Kesehatan Menggunakan Media Cetak dengan Media Audio Visual Terhadap Peningkatan Pengetahuan Pasien Tuberculosis. Jurnal Ilmiah Kesehatan Keperawatan 2011; 7(1): 10.

Maria Angelina Tiurma Br Siahaan, Rosihan Adhani, Emma Yuniarrahmah , 2016. EFEKTIVITAS Kombinasi Demonstrasi Audiovisual Kepada Ibu Tentang Kesehatan Gigi Dan Mulut Terhadap Penurunan Indeks Plak Anak, Dentino jurnal kedokteran gigi, Vol I. No 1. Maret 2016

Muhammad Ilyas, Indah Nisita Putri, 2012. Efek penyuluhan metode demonstrasi menyikat gigi terhadap penurunan indeks plak gigi pada murid sekolah dasar, Dentofasial, Vol.11, No.2, Juni 2012:91-95

Notoatmodjo, S., 2003. Ilmu Kesehatan Masyarakat Prinsip-Prinsip Dasar 2nd ed., Rineka Cipta

Oki N, Eram TP, Bambang W. 2012. Perbandingan media power point dengan flip chart dalam meningkatkan pengetahuan kesehatan gigi dan mulut. Unnes Journal of Public Health. Vol.1. No.12.h.32-35.

Putri I N. Efek penyuluhan kesehatan gigi dan mulut dengan demonstrasi cara menyikat gigi terhadap penurunan indeks plak pada murid kelas VI sekolah dasar. Makasar : FKG UNHAS, 2012. 
Situmorang N. Status dan perilaku pemeliharaan kesehatan gigi dan mulut murid sekolah di 8 Kecamatan di Kota Medan. Dentika Dent J 2008; 2(3): 115-9.

Simons D, Baker P, Jones B, Kidd EAM, Beighton D.:Dental health education: An evaluation of an oral health training programme for carers of the elderly in residential homes. Br Dent J 2010, 188: 206-10.

Yani A. Pengertian penyuluhan kesehatan. $<\mathrm{http}: / /$ id.shvoong.com/medicine-andhealth/epidemiology-public-health/202003pengertian-penyuluhan-kesehatan/> . (10 April 2011) 